own critical judgment he should then write the informative summary in order to focus his mind on the essentials of his message. He will thus discover if he has indeed a worthwhile message to deliver and he will have given himself a clear picture of what is relevant and what is merely incidental to its presentation.

\section{What is next?}

If the evidence is good and the results are interesting, I next wish to know what the authors make of them. Where do they take us? So I turn to the discussion and, if it is convincing I shall next look at the introduction and review of previously published papers on the same subject. Involved discussions of a quasi-philosophical, theological, mystical, or autobiographical nature are not welcome. The discussion needs life and colour. A bit of controversy is good for interest, but it must not be manufactured or forced. It can readily be carried too far; and personality conflicts are out of place. A good discussion will make me read the introduction and review of the literature to see why the work was undertaken and if the paper is really advancing knowledge and understanding. Long preambles are not needed to justify undertaking a piece of investigation, and exhaustive bibliographies are exhausting. Authors have a duty to read other workers' papers and to study them exhaustively but they do not need to prove the extent of their virtue to ordinary readers of journals. Admittedly the matter is different if the reader is the examiner of a thesis; but this is not what we are considering here.

\section{How I subedit}

\section{W F WHIMSTER}

Articles pour into the medical journal offices. The editors try to judge them on their scientific value, but their task is difficult, since in very few does the scientific value shine out completely clearly. The language of most articles makes very hard reading - which does not endear them to the editors. Preparing the accepted articles for the printers is hard work too; that is the job of the subeditor, be he employed by the journal or freelance, professional or amateur.

As a freelance subeditor or language supervisor, mainly for articles written by authors whose native language is not English, I have tried to identify the criteria I use to improve clarity. In fact, I find that I am looking to see whether the authors have applied the advice given by the other contributors to this symposium.

I start by cutting away the verbiage until I can answer "Why did he start?" in the introduction (easily the worst done section); "What did he do?" in the methods section; "What did he find?" among the results; and "What does it mean ?" in the discussion. Journal club members have many good opportunities to practise this-and will find themselves rejecting from their discussions many published articles because the answers are not there. I am aware, of course, that it is easy for a subeditor such as myself to change the meaning-I make my suggestions in pencil on the page so that the author or editor can erase them if they disagree with the new meaning.

I look at the grammar in a simple way-checking all verbs for

Department of Pathology, King's College Hospital, London SE5 9RS W F WHIMSTER, MRCP, MRCPATH, senior lecturer
Lastly, if I am engaged in the authors' field of work, I shall want to read their methods carefully and critically. Standard methods may be cited by reference, but new ones or modifications of established ones must be given in enough detail to allow interested persons to repeat them accurately. When I was responsible for honours students, I found it a good exercise for them to try to repeat new methods described in papers relevant to their studies. Almost always, the methods were either incompletely or inaccurately described and could be reproduced only after correspondence with their authors.

\section{Discussion}

Keeping up to date is a responsibility in which doctors often fail their patients. Of course, doctors are busy, but they are bad doctors if they stop reading about their subject. Writers must make their articles readable if they are to be read; and they must realise the competitive nature of their quest for readers. During my active professional life I necessarily read a great deal-at home, in trains and buses, in the laboratory and office; but I never read as much as some applicants for posts claimed that they did. Latterly, I read two weekly journals and two periodicals (I had better not say which) besides many manuscripts, reports, contents lists, abstracts, and reprints. I had to be highly selective, and I proceeded as described in this paper through title, summary, results, discussion, introduction, and review of the literature to methods and material in that order. If it helps writers of papers to have this account of one reader's approach I have reached my objective.

their subjects; all pronouns for their nouns; all adjectives and adjectival clauses to see what noun they are telling me more about; all adverbs and adverbial clauses for the verbs they modify; and I examine every dull passive construction to see if it can be made active. I reject circumlocutions, woolly words, abbreviations (most readers cannot remember what they mean), and pomp, unless it is on purpose. The passage which follows shows many common examples of all of these failings, while the succeeding list shows how these infelicities may be improved. One has to be careful not to be carried away by this sort of thing, and it may need more than one attempt.

\title{
Introduction
}

Approximately 200 grammes of boro-lithium activated charcoal (BLAC) are needed in order to treat each severe case of A phalloides poisoning at the present moment. Ford et al (1975) were of the same opinion but they anticipated that deactivator coated charcoal would be of assistance to a wider spectrum of patients at some future date.

After treatment commences the urine becomes black in colour comparatively frequently and a considerable proportion of patients demonstrate skin rashes due to the fact that $B L A C$ still contains impurities. It may be noted from the literature that during the time the rash lasts the serum charcoal level is elevated in excess of $20 \mathrm{mg} / 100 \mathrm{ml}$. It is also probable that the blood supply to the lower limbs is significantly decreased relative to the upper limbs in females on contraceptive therapy.

In this situation it seemed to the present writers that, as already stated, more sophisticated forms of charcoal therapy could be developed, and they theorised that experiments in which rats were sacrificed following charcoal dialysis would reveal new data about the interactions between charcoal and the new pomp-deactivator, Medipen.

In this communication... 
Original

Approximately

n order to treat

At the present moment

Were of the same opinion

Anticipated

Spectrum (technical term)

At some future date

Commences

Black in colou

Comparatively

A considerable proportion

Demonstrate

Due to the fact that

It may be noted that

The literature

During the time that

Level

Elevated in excess of

It is also probable

Lower limbs

Significantly (technical term)

Decreased relative to

Upper limb

In this situation

It seemed to the present writers

As already stated

Sophisticated

Theorised

Sacrificed

Following

Reveal

Communication

\begin{tabular}{l} 
Clearer/less pompous \\
About \\
To treat \\
At present, now \\
Agreed \\
Expected \\
Help \\
Range \\
In the future \\
Begins, starts \\
Black \\
-omit \\
Many \\
Develop, have \\
Rashes \\
Because \\
Boro-lithium activated charcoal \\
Oomit \\
Other workers have reported \\
While \\
Concentration \\
Above \\
Probably \\
Legs \\
Noticeably, markedly \\
Lower than \\
Arms \\
Women \\
Gomit \\
We thought \\
Advanit \\
Suggested, argued \\
Killed \\
After \\
Give \\
Facts \\
Paper, article \\
\hline
\end{tabular}

I have illustrated these simple techniques because I am sure that each author, however eminent, should learn to do his "subediting" himself. Books often do not get any subediting at all. As it is extremely difficult to do this objectively on one's own writing, he should then enlist the help of a sympathetic colleague who also knows the rules. The colleague should go through it in front of the author, quizzing him on every point that is not absolutely clear. As this dialogue may become quite acrimonious, it is best for the colleague, however senior, to agree to a return match on his next paper. In this way differences in experience can be made constructive rather than destructive. Unintentional changes of meaning are avoided by this tête à tête verbal method, which is much better than the use of a remote subeditor. The latter can then get on with making the paper conform to the house style of the journal and with preparing the script for the printers. The remote subeditor is also spared the embarrassment of dissecting the verbiage only to find that the content is very small. With papers from non-English-speaking countries the subeditor will still have to spend some time in making the paper sound English to English ears, but this is a relatively minor task if the paper is well constructed in the first place.

As a pathologist I am naturally fascinated by the most elephantine example of any condition and conclude with a true one (though altered to disguise it) on which readers may spend a few happy minutes practising their subediting technique.

It is suffice to say that although substantial data has been presented demonstrating the antigenicity as well as the presence of tissue and species-specific antigens of prostatic tissue and other associated adnexal glands tissue of reproduction of the various species studied, the demonstration of the presence of tumor specific antibodies, or for that matter, circulating antibodies to prostatic tissue or secretions by the methods of precipitation and of passive haemagglutination in the sera of patients with benign or malignant diseases of the prostate and/or following cryosurgical prostatectomy has been, despite histologic and roentgenologic observations of the remission of distant metastases in cases of metastatic adenocarcinoma of the prostate (stage 3) following the cryosurgical treatment of the primary prostatic tumor, for the most part discouraging.

\section{How I write a paper}

\section{ALEX PATON}

Don't believe people who tell you that writing is easy. Except for the fortunate few, writers are made, not born, and the fashioning is a painful process-a very private struggle between you and a blank sheet of paper. Fortunately for the medical author there are certain guidelines and plenty of advice, but the challenge remains. Doing the research or collecting case material is child's play compared with the moment of truth when you come to write up (or down) your results. But given that you have something worth saying-and too many papers seem to be written because someone other than the author thought it would be a good idea-get down to it, learn a few basic rules, and write-and write.

\section{The structure}

The writer of scientific and medical papers has the advantage of a ready-made scaffold on which to build. This is the IMRAD structure and corresponds with the questions (table) which Sir Austin Bradford Hill said an author should try to answer. If you wish you can start with the Introduction and work straight through, but you don't have to. Sometimes I find it easier to begin with Results, because this is the core around which the rest of the argument can be written. Most introductions need

Dudley Road Hospital, Birmingham B18 7QH

ALEX PATON, MD, FRCP, consultant physician only a couple of paragraphs, at the most; they do not require a review of "the literature." Materials (or Patients) and Methods should also be short. You do not need to give details of common techniques, but if your work is based on a new method you

Structure of an article (Imrad)

$\begin{array}{lc} & \text { SUMMARY } \\ \text { I ntroduction } & \text { Why did you start ? } \\ \text { M ethod } & \text { What did you do ? } \\ \text { R esults } & \text { What did you find? } \\ \text { A nd } & \text { What does it mean? } \\ \text { D iscussion } & \text { What }\end{array}$

must provide adequate details so that others can repeat it. This is not always done with sufficient care, and gives rise to a suspicion, no doubt entirely false, that the author does not want other people to verify his work. Results are results. One of the commonest faults is to introduce snippets of interpretation into this section; the proper place for them is in the discussion. The Discussion is always difficult. If you are stuck, begin by giving your results in the light of other people's findings, proceed to discuss their meaning, and end by stating how they alter or advance current ideas. If possible, indicate future lines of research.

There is no need to sum up or conclude at the end of the discussion. Most journals now print a Summary at the beginning of the paper, and this is often the only part that people read. Take as much trouble (or more) over composing the summary as in writing the paper. It must contain the points that you wish to get 